\title{
Analysis Microstructural on Gray Cast Iron Boriding and Hydrogen of Permeation
}

\author{
I. López Velázquez ${ }^{1 *}$ N. Lopez-Perrusquia ${ }^{1}$, M. A. Doñu-Ruiz ${ }^{1}$ and E. D. García Bustos ${ }^{2}$ \\ 1. Universidad Politécnica del Valle de México, Grupo Ciencia e Ingeniería de Materiales, Tultitlán, \\ Estado de México. \\ 2. Cátedras-CONACYT, Centro Universitario de Ciencias Exactas e Ingenierías (CUCEI), Universidad \\ de Guadalajara, Guadalajara, Jalisco, México. \\ * Corresponding author: noeperrusquia@hotmail.com
}

The need nuclear engineering is to improve the characteristics of ferrous and non-ferrous materials by innovation of layers resistant to hydrogen irradiation, permeation and embrittlement [1-2]. Also the need for resistant layers with the interaction of hydrogen are of interest for industries petroleum, naval, automotive and agriculture, which need innovative materials with layers to mitigate the effect of hydrogen [3-4]. The results presented the properties microstructural of surface and Mechanical, can assist in the selection and design for hydrogen mitigation in the nuclear engineering, manufacturing engineering and product engineering.

We have described the growths of formed layers $\mathrm{FeB} / \mathrm{Fe}_{2} \mathrm{~B}$ and the influence layers $\mathrm{FeB} / \mathrm{Fe}_{2} \mathrm{~B}$ on permeation of hydrogen. The material for this study is a gray cast iron, composition $5.40 \% \mathrm{C}, 1.378 \%$ Si, $0.630 \% \mathrm{Mn}, 0.1646 \% \mathrm{Cr}, 0.050 \% \mathrm{Mo}, 0.3662 \% \mathrm{Cu}$; dimensions $3.8 \mathrm{~mm}$ long, $5 \mathrm{~mm}$ wide and $3 \mathrm{~mm}$ thick; with a notch at $45^{\circ}$, The formation microstructural of surface on gray cast by boron paste dehydrated at temperature of $1193 \mathrm{~K}$ for 8 hours exposure time. The microstructure of surface layers after boriding it was studied using; Scanning Electron Microscope and Energy Dispersive Spectroscopy (EDS-MEB to $100 \mathrm{kV}$ - JEOL $6063 \mathrm{~L}$ ), Optical Microscopy Olympus (GX 51) and determination of the present layers, XRD analysis was performed on the $\mathrm{Cu} \mathrm{K} \alpha$-hardened parts and a $\lambda 1.54 \mathrm{~A}$ (Bruker D8 Advance). The evaluation hardness using an Ultra Micro Hardness Tester Mitutoyo; indentation loads to $200 \mathrm{mN}$. Hydrogen was produced in the charge cell via a galvanostatic method with a current density of $50 \mathrm{~mA} \cdot \mathrm{cm} 2$ and the solution consisted of $0.5 \mathrm{M}$ sulfuric acid (H2S04) dissolved in double distilled water added with five drops of carbon disulphide (CS2); time of 6 hours of hydrogen loading. The evaluation mechanical using Instron model 8502, velocity of advance $0.102 \mathrm{~mm} / \mathrm{min}$. The Figure 1a revealed the growth of microestructural of layers $\mathrm{FeB} / \mathrm{Fe} 2 \mathrm{~B}$, and sawn morphology layers. EDS-SEM micrographs revealed the presence $\mathrm{FeB}, / \mathrm{Fe}_{2} \mathrm{~B}$ as observed Figure $1 \mathrm{~b}$ with layers to $105 \pm 12.9 \mu \mathrm{m}$. The Figure 2 shows the existence $\mathrm{FeB}, \mathrm{Fe}_{2} \mathrm{~B}, \mathrm{CrB}$ and $\mathrm{SiB}_{6}$, result of $\mathrm{XRD}$ pattern on a range from $20^{\circ}$ to $100^{\circ}$. The hardness results are 1887 to $1969(\mathrm{Hv})$ and the elastic modulus results are 268-271 (GPa). Table 1 shows effect of Hydrogen permeation on the gray cast iron boriding. This process of boron dehydrated paste presents the analysis microestructural of the layers $\mathrm{FeB} / \mathrm{Fe}_{2} \mathrm{~B}$ resistance for mitigation hydrogen.

References:

[1] P Korinko, Microscopy and Microanalysis 10 (2004), p. 618.

[2] AV Belyakov et. al., Surface Engineering and Applied Electrochemistry 53 (2017), p. 274.

[3] O Barrera et al., Journal of Materials Science 53 (2018), p. 6251.

[4] J Toribio et al., Engineering Failure Analysis 82 (2017), p. 458. 

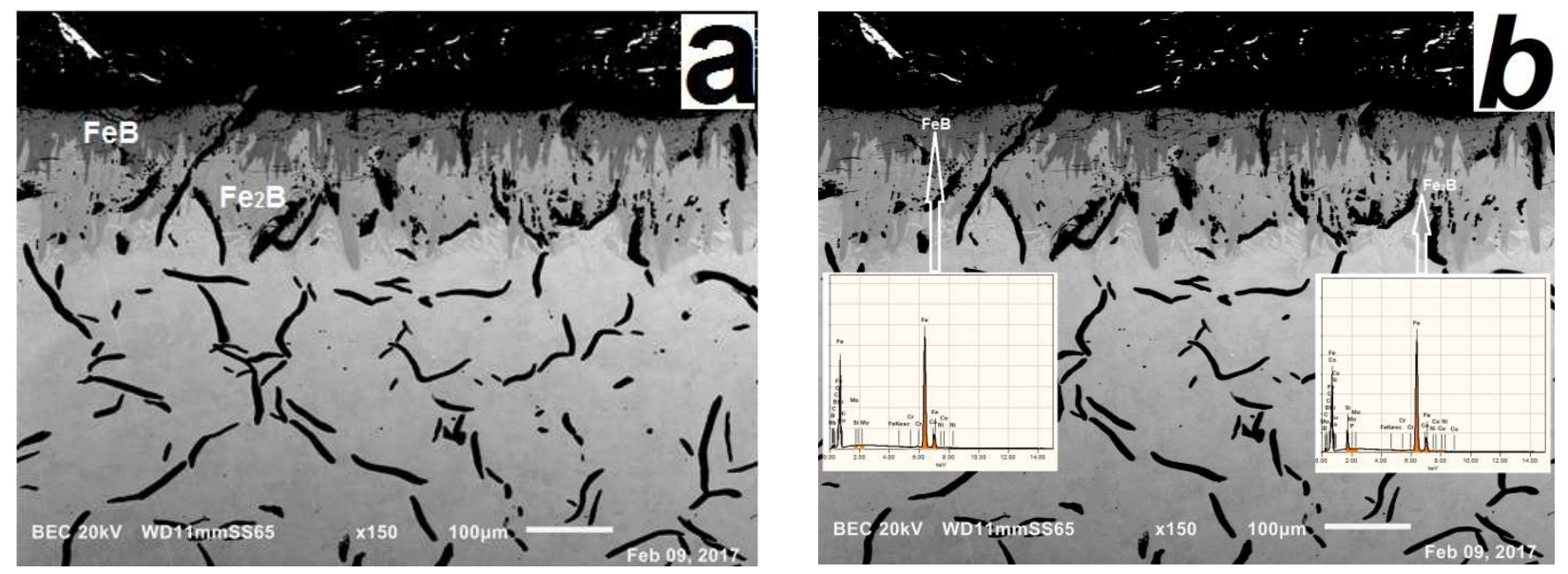

Figure 1. (a) SEM micrographs showing iron borided in the gray cast iron and (b) cross-sectional micrograph and EDS analysis at surface of $\mathrm{FeB}$ and $\mathrm{Fe}_{2} \mathrm{~B}$ by 8 hours of treatment at temperature 1193 K.

\begin{tabular}{|c|c|c|c|}
\hline $\mathrm{FeB}$ & & & \\
\hline $2 t h$ & $h$ & $k$ & $l$ \\
\hline 32.9 & 2 & 0 & 0 \\
\hline 38.0 & 0 & 1 & 1 \\
\hline 39.7 & 2 & 0 & 1 \\
\hline 41.5 & 1 & 1 & 1 \\
\hline 45.1 & 2 & 1 & 0 \\
\hline 47.9 & 1 & 0 & 2 \\
\hline 50.8 & 2 & 1 & 1 \\
\hline 55.1 & 3 & 0 & 1 \\
\hline 57.5 & 1 & 1 & 2 \\
\hline 63.0 & 0 & 2 & 0 \\
\hline 72.6 & 4 & 0 & 1 \\
\hline 77.0 & 2 & 2 & 1 \\
\hline 77.2 & 3 & 1 & 2 \\
\hline 83.0 & 1 & 2 & 2 \\
\hline
\end{tabular}

\begin{tabular}{|c|c|c|c|}
\hline \multicolumn{4}{|c|}{$\mathrm{Fe}_{2} \mathrm{~B}$} \\
\hline $2 t h$ & $h$ & $k$ & $l$ \\
\hline 45.1 & 2 & 1 & 1 \\
\hline 50.8 & 2 & 2 & 0 \\
\hline
\end{tabular}

\begin{tabular}{|c|c|c|c|}
\hline \multicolumn{3}{|c|}{$\boldsymbol{C} \boldsymbol{B} \boldsymbol{~}$} \\
\hline $\boldsymbol{2} \boldsymbol{t} \boldsymbol{h}$ & $\boldsymbol{h}$ & $\boldsymbol{k}$ & $\boldsymbol{l}$ \\
\hline 32.9 & 1 & 1 & 0 \\
\hline 38.0 & 0 & 2 & 1 \\
\hline 63.0 & 0 & 0 & 2 \\
\hline 72.6 & 0 & 6 & 0 \\
\hline
\end{tabular}

\begin{tabular}{|c|c|c|c|}
\hline \multicolumn{4}{|c|}{$\mathrm{SiB}_{6}$} \\
\hline $2 \boldsymbol{t} \boldsymbol{h}$ & $\boldsymbol{h}$ & $\boldsymbol{k}$ & $\boldsymbol{l}$ \\
\hline 28.5 & 3 & 4 & 1 \\
\hline
\end{tabular}

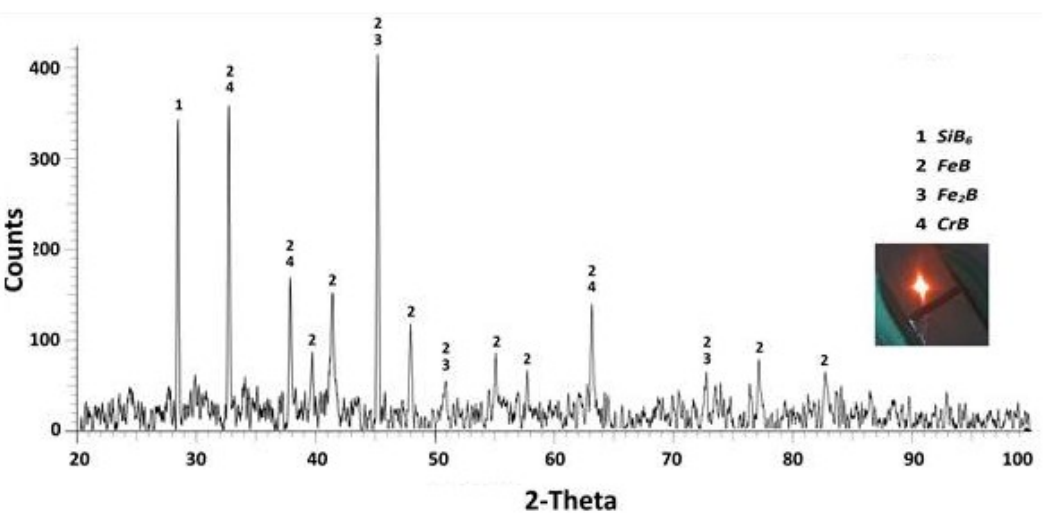

Figure 2. X-ray diffraction patterns obtained by the laser indicate the test site on the gray cast iron borided at $1193 \mathrm{~K}$ for 8 hours.

\begin{tabular}{clcc}
\hline Materials & $\begin{array}{c}\text { Conditions } \\
\text { (Charged with hydrogen) }\end{array}$ & $\begin{array}{c}\text { Stress } \\
\text { (Mpa) }\end{array}$ & $\begin{array}{c}\text { Strain } \\
\mathbf{( \% )}\end{array}$ \\
\hline Cast iron Gray & Without Boriding & 42.36 & 0.379 \\
Cast iron Gray & Boriding 1193K, with 8 h. & 153.08 & 0.590 \\
\hline
\end{tabular}

Table 1. Effect of Hydrogen permeation on el cast iron gray borided 